\title{
SOCIAL PARADIGM SHIFT REQUIRED TO COUNTER THE EUTROPHICATION OF THE HARTBEESPOORT DAM IN SOUTH AFRICA
}

\author{
INGRID DENNIS \& STEFANUS RAINIER DENNIS \\ Centre for Water Sciences and Management, North-West University, South Africa
}

\begin{abstract}
Sewage discharges are poisoning major rivers and dams in South Africa, including the Hartbeespoort Dam. High nutrient concentrations promote algae growth, leading to eutrophication. The dam has been in a hypertrophic state since the early 1970s. Mismanagement of waste water treatment works (WWTWs) within the catchment area are largely to blame, with over 280 tons of phosphate and nitrate deposits. Point source pollution in the form of malfunctioning WWTWs and diffuse sources from informal settlements present along streams and rivers within the catchment area, are responsible for the high nutrient levels. Many of these settlements use water directly from the river/stream. The first step to address the problem of eutrophication is by reducing the nutrient source. A conservative mass transport model was developed to predict phosphate levels and was used to assess the impact on the dam. The average phosphate levels entering the dam is $0.72 \mathrm{mg} / \mathrm{L}$ and the target to reduce algae growth is $0.15 \mathrm{mg} / \mathrm{L}$. Various treatment options were investigated to solve the problem, but these efforts were mainly focused on treating the symptoms rather than the cause and treatment options were very costly. Legislation regarding water pollution this is in place, but is not enforced by government. The model predictions indicate that even if all WWTWs reach a zero discharge of phosphates, the required target will still not be met. It is concluded that the only feasible option would be a paradigm shift in the social behaviour of people living in informal settlements and this paradigm shift requires education. More often than not, scientists and engineers only consider technical solutions. The result of this study underlines the importance of a transdisciplinary approach, involving scientists and the rural communities to reach an effective solution.
\end{abstract}

Keywords: sewage discharges, social injustice, informal settlements, phosphate, transdisciplinary approach.

\section{INTRODUCTION}

South Africa is viewed as a water-stressed country with an average annual rainfall of $500 \mathrm{~mm}$. Available water resources are already being intensively used and controlled. Seven of South Africa's nine provinces rely on inter-basin transfers which provide more than half of their water requirements [1].

\subsection{The Hartbeespoort Dam}

The Hartbeespoort Dam is an arch type dam situated in the North West Province of South Africa. It lies in a valley to the south of the Magaliesberg mountain range and north of the Witwatersrand mountain range, about $35 \mathrm{~km}$ north west of Johannesburg and $20 \mathrm{~km}$ west of Pretoria.

The Hartbeespoort Dam was designed for irrigation purposes, which is currently its primary use, as well as for domestic and industrial use. The catchment landcover and the associated WWTWs is shown in Fig. 1. It is clear that the majority of land use consists of agricultural irrigation and urban areas, with some scattered informal settlements. 


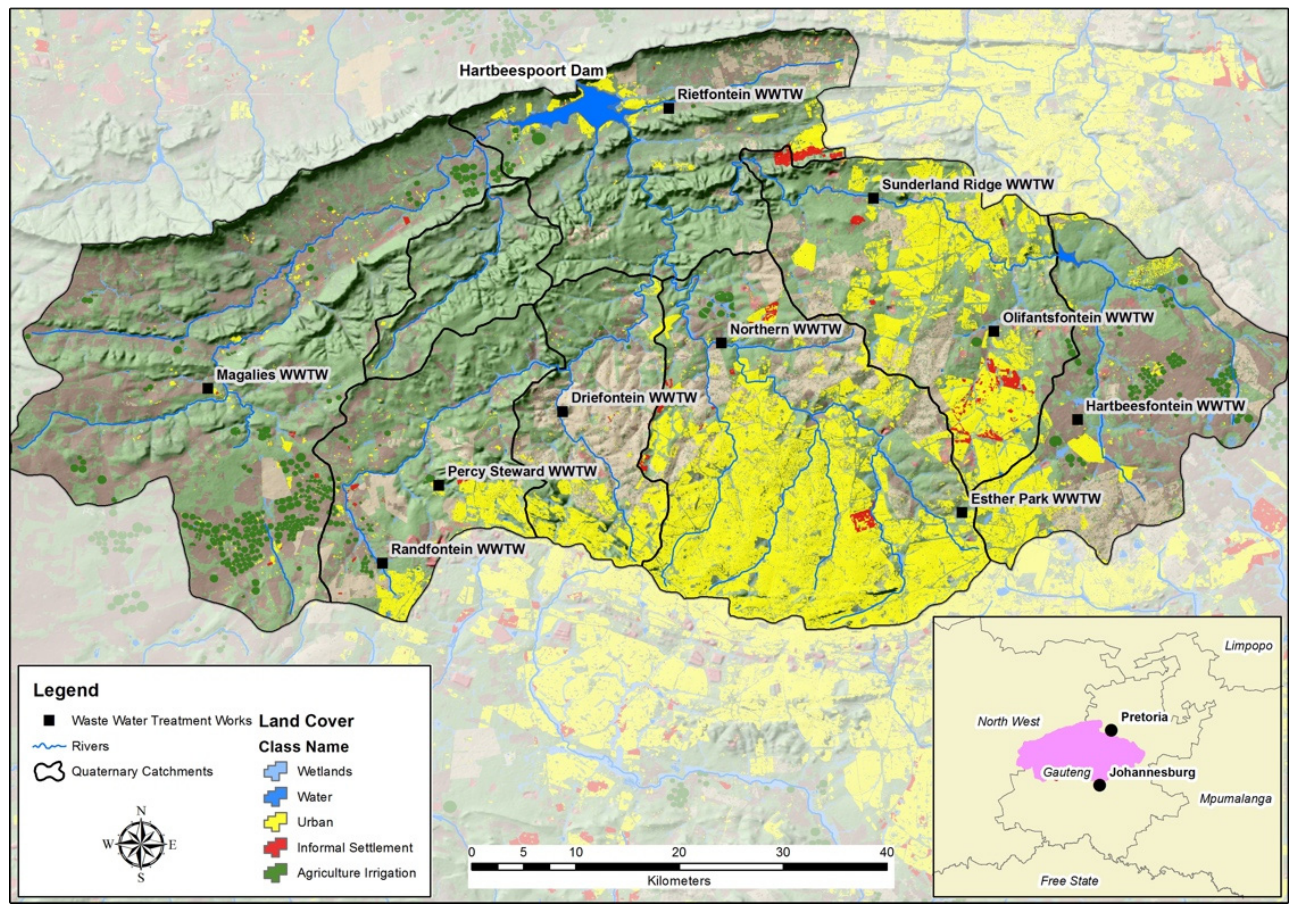

Figure 1: Hartbeespoort Dam catchment and WWTWs [20].

The dam has suffered from a hypertrophic state (excessive levels of nutrients) since the early 1970s. Mismanagement of waste water treatment from urban areas within the Hartbeespoort Dam catchment is largely to blame, having distorted the food web with over 280 tons of phosphate and nitrate deposits [2]. A total of ten WWTWs exist within the catchment of which some are known to be problematic [3].

Various scientific reports determined that phosphates and nitrates originating from sewage treatment plants in the catchment are the main source of nutrients involved in eutrophication [4]. Estimated phosphate concentrations from effluent together with the operating capacity (OC) for the various WWTWs are documented in Table 1. The extreme level of eutrophication is evident in excessive growth of microscopic algae, cyanobacteria, and water hyacinth as shown in Fig. 2.

Table 1: WWTW phosphate concentrations and operating capacities.

\begin{tabular}{|l|c|c|l|c|c|}
\hline $\begin{array}{l}\text { Waste water } \\
\text { treatment works }\end{array}$ & $\begin{array}{c}\mathrm{OC} \\
(\mathrm{ML} / \mathrm{d})\end{array}$ & $\begin{array}{c}\mathrm{PO}_{4} \\
(\mathrm{mg} / \mathrm{L})\end{array}$ & $\begin{array}{l}\text { Waste water } \\
\text { treatment works }\end{array}$ & $\begin{array}{c}\mathrm{OC} \\
(\mathrm{ML} / \mathrm{d})\end{array}$ & $\begin{array}{c}\mathrm{PO}_{4} \\
(\mathrm{mg} / \mathrm{L})\end{array}$ \\
\hline Driefontein & 30 & 0.17 & Magalies & 0.38 & 5.98 \\
\hline Northern & 390 & 0.30 & Olifantsfontein & 79 & 1.41 \\
\hline Sunderland Ridge & 57 & 1.86 & Hartbeesfontein & 58 & 0.33 \\
\hline Randfontein & 13 & 2.38 & Esther Park & 0.71 & 0.96 \\
\hline Percy Steward & 17 & 1.85 & Rietfontein & 2.5 & 1.26 \\
\hline
\end{tabular}




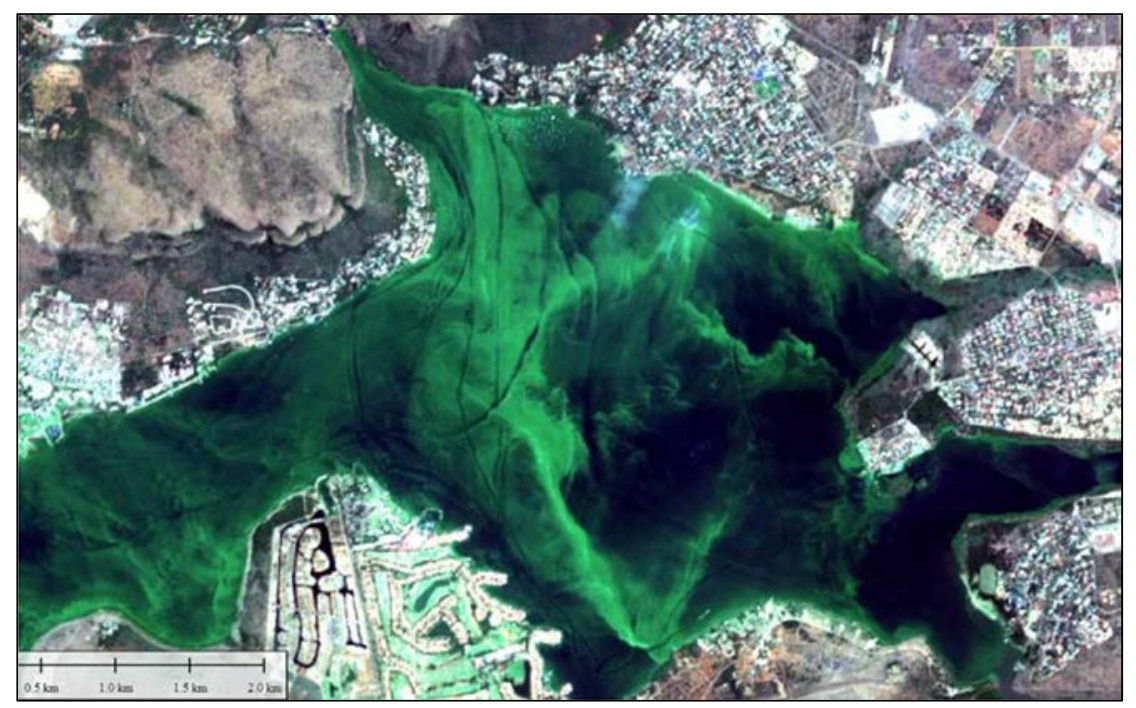

Figure 2: Aerial photo of the Hartbeespoort Dam [21].

\subsection{Rehabilitation efforts}

The Department of Water and Sanitation (DWS) implemented the Hartbeespoort Dam Integrated Biological Remediation Programme, Harties Metsi-a-me (translated: my water), in 2005 [2]. The aim of this programme was to address the imbalances and unhealthy biological conditions in the dam. The implementation was rolled out in two phases; Phase 1 focussed on establishing biological processes and mechanical harvesting of biomass (algae and hyacinths) as shown in Fig. 3 and Phase 2 focused on the treatment and bulk removal of phosphates. The program had various degrees of success, but in the long run it was not successful, due to poor project management. The failure to address mismanagement of WWTWs upstream of the dam before mitigation activities commenced, is one of the main reasons for this failure [5].

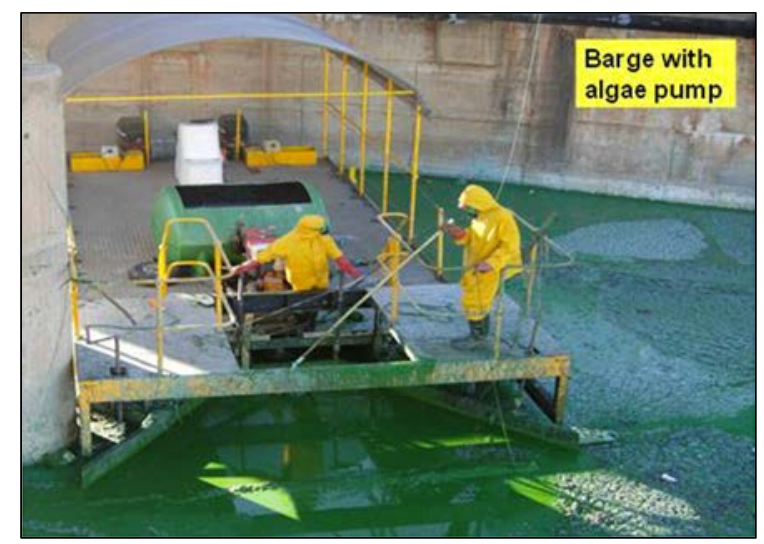

Figure 3: Algae harvesting barge [22]. 


\subsection{Social justice}

With the appointment of Nelson Mandela as President in 1994, a new era in the history of South Africa commenced. One of the first changes made by the new Minster of Water Affairs and Forestry, was to revolutionise the Water Act based on the rationale that water belongs to all South Africans, with sustainability, equity and efficiency being the guiding principles, or more simplistically "Some for all forever" [6].

Even though claims have been made that the South African National Water Act is one of the best in the world, the enforcement thereof remains a challenge. According to legislation, it mandatory that effluent discharge from WWTWs be treated to acceptable standards and returned to the water course from where it originated [4]. Clearly this is not the case in the Hartbeespoort catchment as is evident in media reports [5], [7]. The declining state of wastewater and sewage treatment infrastructure is contributing to the numerous pollution problems, including health problems in poorer communities [8].

Approximately $52 \%$ of poor underprivileged South Africans live in informal settlements [9]. These settlements tend to be unplanned and poorly serviced as in the case of settlements in the vicinity of the Hartbeespoort Dam. An example of one, is an informal settlements along the Jukskei River, which is a tributary of the Crocodile River reporting to the Hartbeesport Dam (Fig. 4).

Over the last 30 years, South Africa experienced rebellion of the poor [10]. The majority of these protests relate to poor service delivery (for example the lack of clean drinking water and poor sanitation).

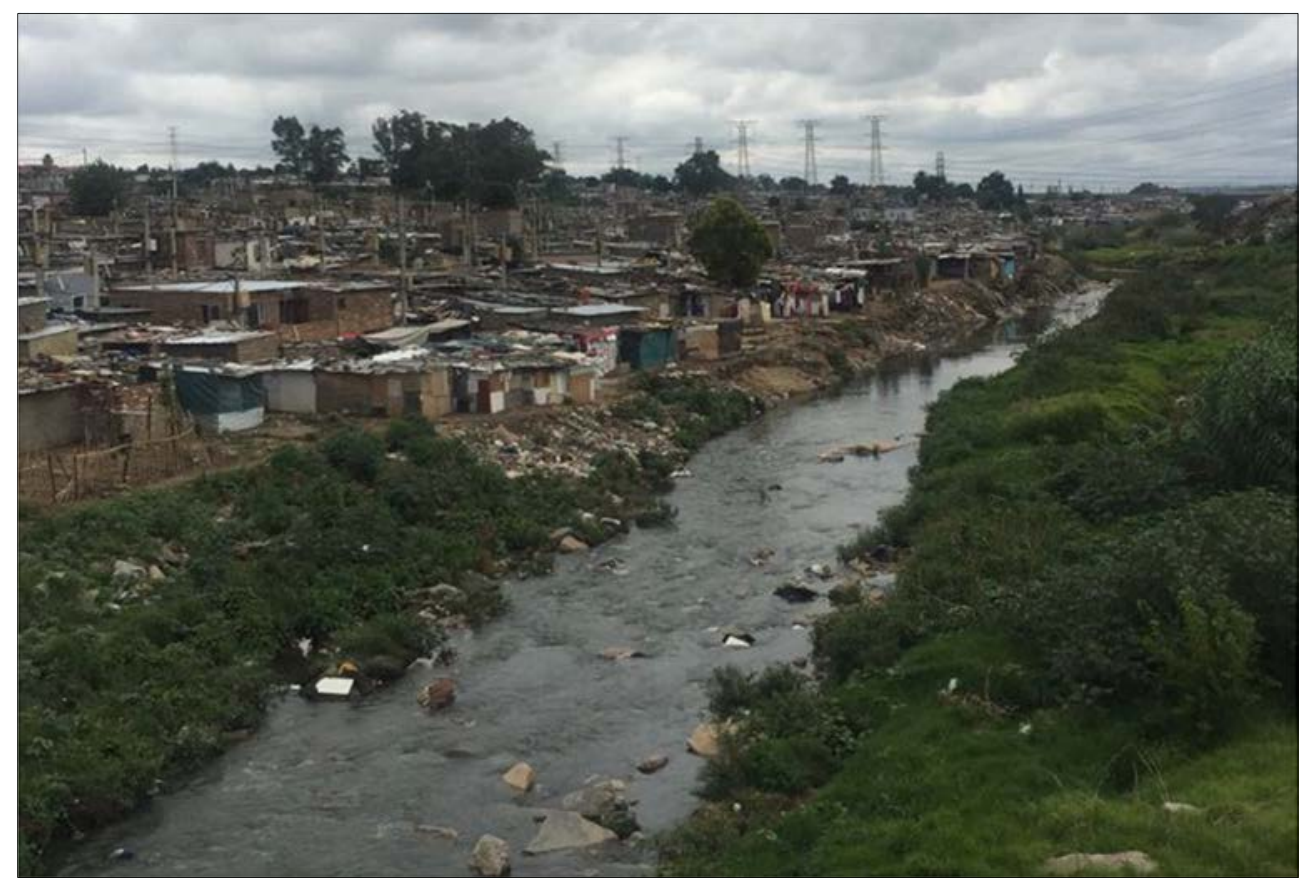

Figure 4: Informal settlement along the Jukskei River [23]. 
In most informal settlements the inhabitants get water from a surface water body close by or groundwater. In the case of a surface water body, it is also the place where they bath and wash their clothes. In many instances pit latrines (Fig. 5) are also in close proximity to water sources, which pose a pollution risk. In the case of shallow groundwater systems, polluted groundwater can seep into downstream surface water bodies.

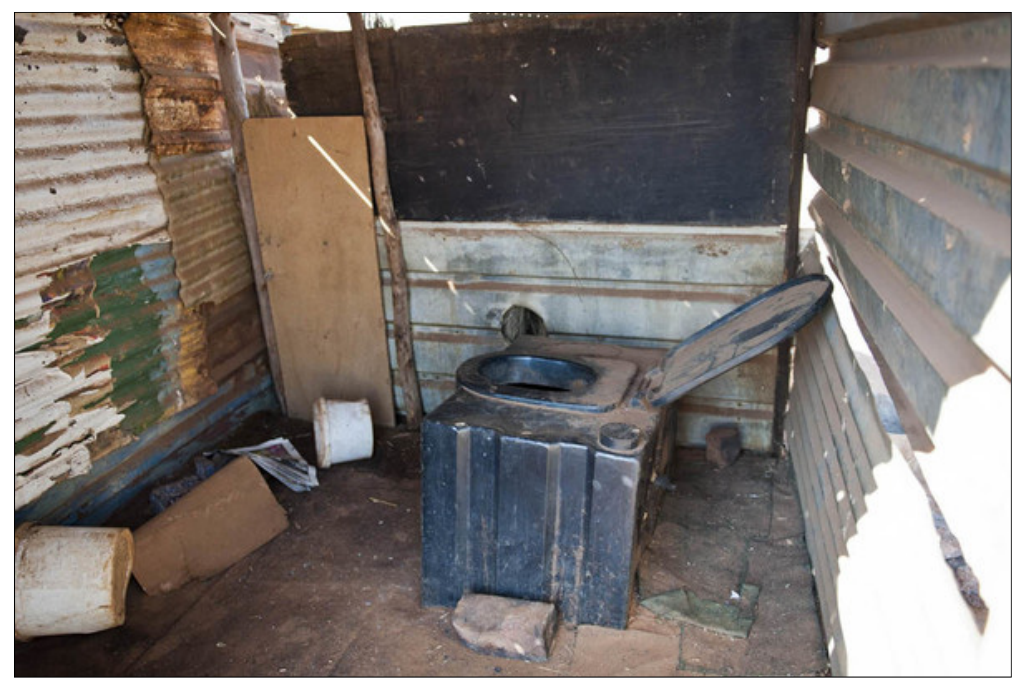

Figure 5: Example of a pit latrine [24].

\section{PROBLEM}

\subsection{Problem statement}

Recent programmes [2] and various research efforts [11], [12] focussed on treatment options for the Hartbeespoort Dam. It has been determined that the phosphate load entering the dam (average $0.73 \mathrm{mg} / \mathrm{L}$ ) should be reduced to $0.15 \mathrm{mg} / \mathrm{L}$ to actively reduce the growth of algae. Being able to model the phosphate load entering the dam, allows for the investigation into individual pollution sources that are impacting the downstream system.

\subsection{Aims and objectives}

The aim of this study is to develop a water quality model to determine the impacts of point source pollution on the Hartbeespoort Dam. The specific focus is the levels of phosphates and how they relate to dysfunctional WWTWs. The objectives of this study are outlined as follows:

- Develop a water quality model to simulate the phosphate levels in the Hartbeespoort catchment.

- Estimate phosphate loads in the system where no data is available.

- Calibrate the model making use of existing monitoring data.

- Determine the impacts of various phosphate sources using the model. 


\section{METHODOLOGY}

\subsection{Flow network data}

To successfully model the phosphate loads in the Hartbeespoort catchment, observation data is required for model calibration. The DWS maintains an online hydrological database with all surface water flow gauging sites in South Africa [13]. In addition to the flow gauging information, water quality measurements are available from the resource quality database [14]. The water resource quality database contains many inconsistencies in chemical analysis results, which the user needs to take into consideration before using the data [15].

In 2011 a snapshot of the water quality database was taken and has been extensively modified, which included the removal of incomplete analyses and the addition of extra chemical variables calculated from concentrations of the major ions [15]. This augmented water quality dataset was chosen for the analysis. The best continuous set of monitoring data across all flow gauges in the Hartbeespoort catchment is October 2007 to July 2011. The associated flow network with gauging sites is shown in Fig. 6.

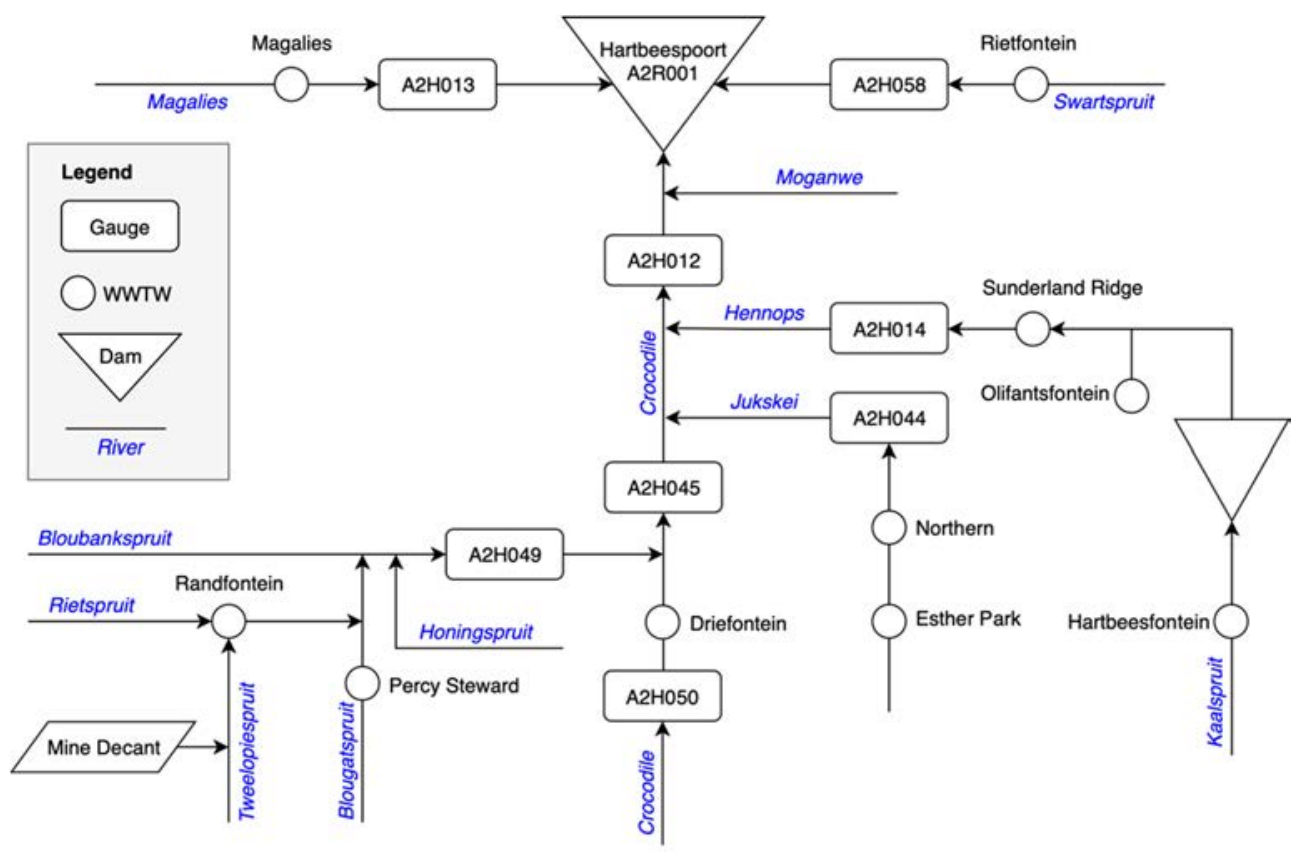

Figure 6: Flow gauging network.

In general, the effluent water qualities and volumes are not readily available for WWTWs. Personnel working at these facilities are reluctant to allow access to the premises for sampling. The only way to get an estimate of discharge qualities is to monitor up- and downstream of the WWTW. Operating capacities and estimated effluent qualities are documented in Table 1. 


\subsection{Model selection}

The available data dictates the model to be used. The flow data is available both in daily and monthly time steps from the DWS hydrological database. Since water quality data is measured in monthly time steps, the selected model will also use monthly time steps for simulation purposes.

Various reactive mass transport model codes are available, but because only major ion analysis data is available, a conservative mass transport model is considered. Since the study requires the modelling of phosphates, the assumption of phosphates being conservative in the system of question should be investigated.

Binding of orthophosphate $\left(\mathrm{FePO}_{4}\right)$ in solution can take place in inflowing waters. However the uptake of $\mathrm{FePO}_{4}$ by algae is more important than the physicochemical processes particularly in the $\mathrm{pH}$ range of 6.0-8.0. The greater the change of the $\mathrm{pH}$ from this range, the more likely $\mathrm{FePO}_{4}$ will combine with iron, aluminium and manganese $($ at $\mathrm{pH}<6$ ) or calcium (at $\mathrm{pH}>8$ ) as shown in Fig. 7 [16].

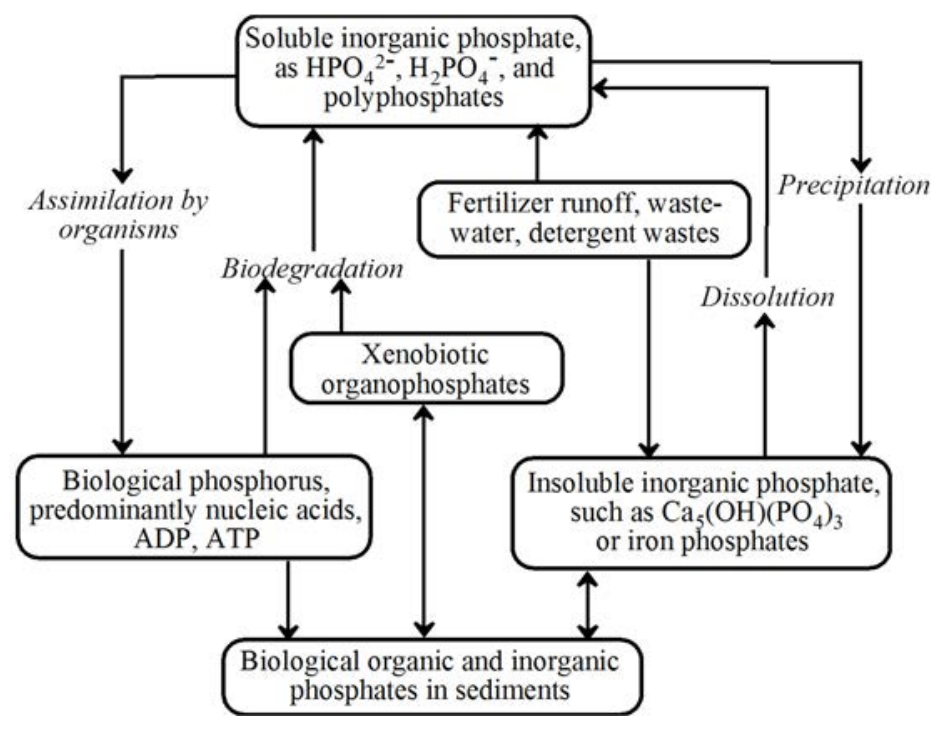

Figure 7: The phosphorous cycle [16].

As the mass transport model will be applied to the water courses and not the reservoir itself, the uptake from algae is not considered. The average $\mathrm{pH}$ across all monitoring points is alkaline and the general $\mathrm{pH}$ range is between 7.5 and 8.5 with a few selected events going as high as 9.1. Chemical binding of phosphates is therefore not completely ruled out, but considered negligible for the purpose of this study.

\subsection{Water quality model}

An alternative method to the traditional method of water quality modelling, is the backtracking approach [17]. This approach differs from the traditional one in that, instead of following the water in a volume element downstream, the system tracks back upstream to find the source concentrations of the pollutants. This scheme is depicted in Fig. 8, where: 
$\mathrm{t}=$ Time step;

$i=$ Number of segments;

$\mathrm{j}=$ Number of concentrations;

$\mathrm{C}=$ Concentration;

$\mathrm{V}=$ Volume;

$\mathrm{k}=$ Decay rate constant;

$\mathrm{T}=$ Water temperature;

$\theta=$ Temperature correction coefficient.

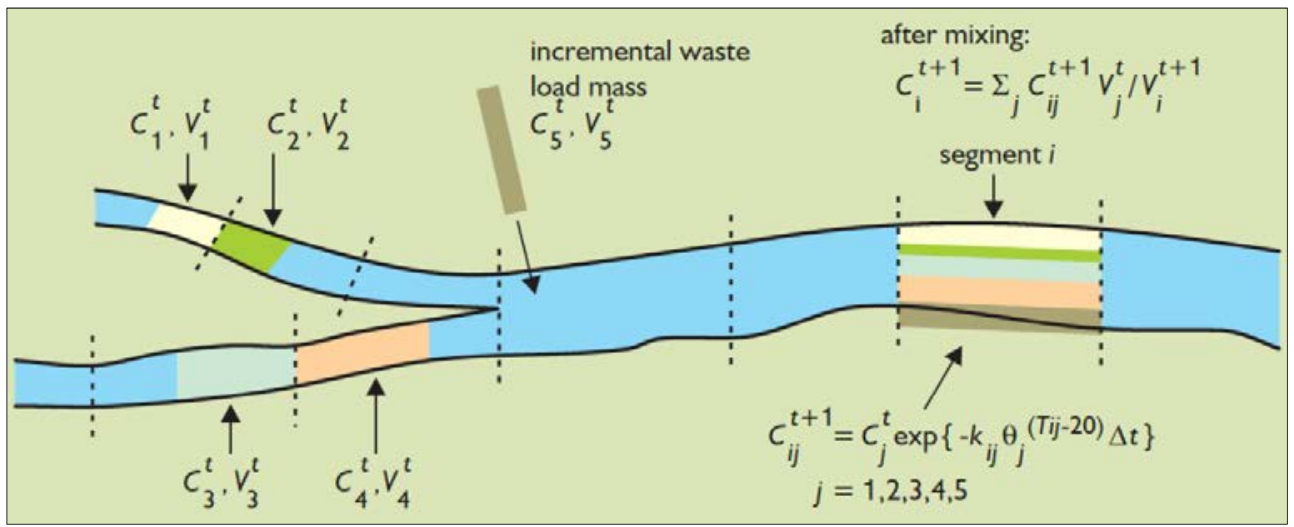

Figure 8: Backtracking approach for computing water quality [17].

Temperature measurements do not form part of the DWS monitoring data. The temperature term $\mathrm{T}_{\mathrm{ij}}$ is chosen to be $20^{\circ} \mathrm{C}$ to effectively eliminate the $\theta$ term. Furthermore, since it was assumed that the phosphate behaves in a conservative manner, no decay will occur and the decay rate constant $\mathrm{k}$, is chosen as zero.

\subsection{Model calibration through genetic algorithm}

Model calibration is carried out by assuming that constant phosphate loads are associated with WWTWs and applying a genetic algorithm (GA) to determine calibration parameters.

Genetic algorithms are randomized general-purpose search techniques used for finding the best values for parameters of existing models [17]. Unlike conventional optimization search approaches based on gradients, GAs work on a population of possible solutions, attempting to find a solution set that either maximizes or minimizes the value of a function of those solution values [18].

The parameter estimation, carried out by the GA, considers each parameter in question as a binary string where the length of the string $n$ determines the maximum integer value that can be represented through $2^{\mathrm{n}}$. This binary parameter is then typically scaled between a minimum and maximum value. Karr et al. [18] notes that an additional bit can added to the binary string to represent the sign of the number. Finally, the individual parameter strings are concatenated to represent a single solution to the problem.

Initially the GA generates a random population of these solution strings, where each represents a potential solution to the problem. The problem in this instance is optimising the fit between simulated and observed values in the water quality model. The GA mimics the 
biological evolutionary process, where the binary solution string is considered a chromosome and each bit represents a gene. Once a chromosome (solution string) is generated, the individual parameters can be extracted from it and applied to the model to produce a result which is evaluated in terms of its fitness as a solution to the problem.

Reproduction is carried out by selecting only the chromosomes that provided the best fit to the problem. Various selection methods exist e.g. Elitist, Random, Roulette, Stochastic tournament and Tournament to name a few. New chromosomes are then constructed via a process called cross-over, where a random number of genes are swopped from two of the selected chromosomes to construct a new chromosome as shown in Fig. 9. This process allows random variation of the strongest chromosomes to be generated.

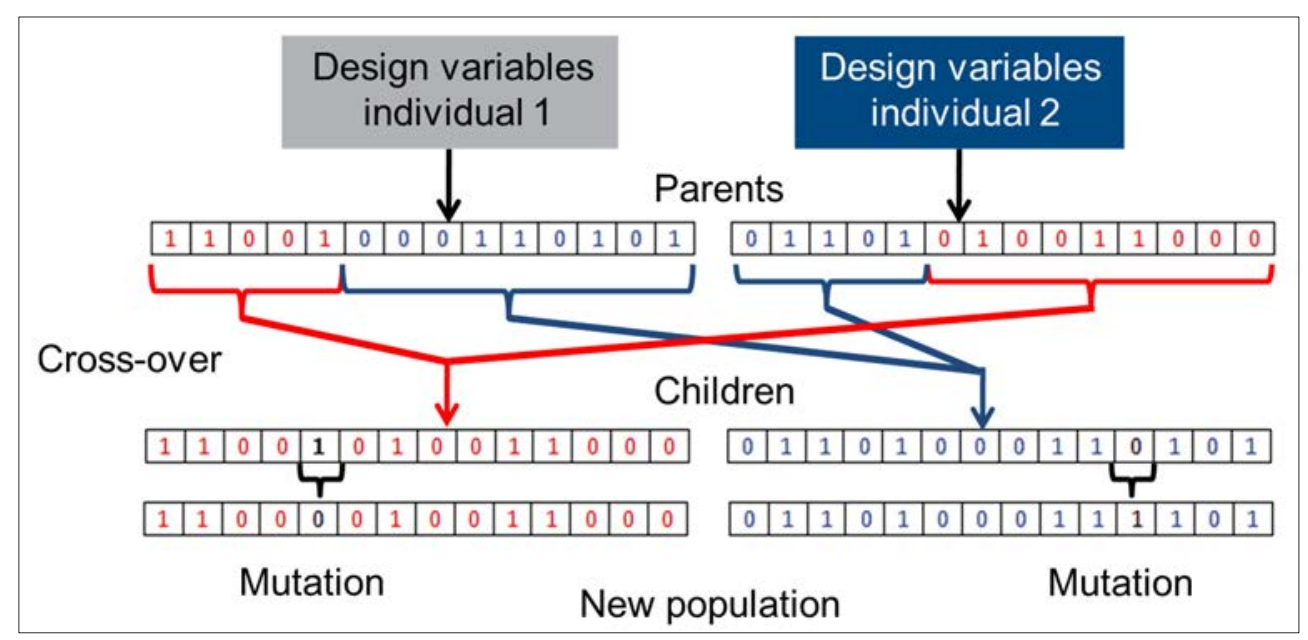

Figure 9: Crossover between two genotypes [25].

The last process of the GA, before it repeats itself, is mutation where a random bit in the newly created chromosome is toggled from its current value. This process is only applied to a small part of the total population to ensure an optimal solution is reached. Consider the case where none of the chromosomes had a specific gene in the same position, reproduction and crossover will never result in the presence of this specific gene, therefore the need for mutation.

The GA process is repeated until an acceptable goodness of fit is reached for the problem. Two statistical equations are used to quantify the goodness of fit between simulated and observed values, namely the Root Mean Square Error (RSME) and the Nash-Sutcliffe Coefficient (NSC). The RMSE is a frequently used error index, where it is generally accepted that the lower RSME value represents a better model fit than a higher RMSE value and is expressed in eqn (1)

$$
\text { RMSE }=\sqrt{\frac{\sum\left(P_{i}-O_{i}\right)^{2}}{n}},
$$

where:

$\mathrm{i}=$ Total number of observation points;

$\mathrm{P}_{\mathrm{i}}=$ Predicted value at point $\mathrm{i}$; 
$\mathrm{O}_{\mathrm{i}}=$ Observed value at point $\mathrm{i}$;

$\mathrm{n}=$ Number of reference points.

The NSC is a widely used statistical method to compare the predictive capability of a hydrologic model, it shows how well a hydrologic model performs. The NSC compares both the volume and the shape of the runoff and is expressed in eqn (2)

$$
N S C=1-\frac{\sum_{i=n}^{n}(O i-P i)^{2}}{\sum_{i=n}^{n}(O i-\bar{O})^{2}}
$$

where:

$\mathrm{i}=$ Total number of observation points;

$\mathrm{P}_{\mathrm{i}}=$ Predicted value;

$\mathrm{O}_{\mathrm{i}}=$ The observed values for the $\mathrm{n}$ observations;

$\overline{\mathrm{O}}=$ The mean of the observed values.

The NSC ranges between $-\infty$ and 1 and values ranging between $0.75<\mathrm{NSC} \leq 1.00$ are classified as very good, values between $0.65<\mathrm{NSC} \leq 0.75$ classified as good, values between $0.50<\mathrm{NSC} \leq 0.65$ classified as satisfactory and values of NSC $\leq 0.50$ as unsatisfactory.

\section{RESULTS AND DISCUSSION}

\subsection{Calibration results}

Both RMSE and Nash-Sutcliffe methods were considered as goodness-of-fit criteria for use in the GA together with the use of the five selection methods mentioned previously. The best results were obtained my making use of the RMSE as minimization criteria together with the Elitist selection algorithm.

The network calibration results are shown in Fig. 10. Good calibration is achieved throughout the network with respect to flow. The model only over predicts the final average flow at A2R001 (Hartbeespoort Dam) with 4.6\%.

The phosphate calibration results are satisfactory for most of the gauge positions with the exception of $\mathrm{A} 2 \mathrm{H} 013$ and $\mathrm{A} 2 \mathrm{H} 049$. The differences between the observed and measured phosphate concentrations at $\mathrm{A} 2 \mathrm{H} 013$ and $\mathrm{A} 2 \mathrm{H} 049$ can be attributed to the fact that phosphate loads at the WWTWs are modelled as a constant, as no actual time series discharge volumes and water quality data is available. This is also the case for the mine decant taking place upstream of A2H049. The phosphate concentrations at A2H013 is the lowest of all the gauges considered and represents only $0.02 \%$ of the phosphate load at A2R001. The model over predicts the average phosphate concentration at A2R001 with $5.2 \%$ and the average phosphate load with $10.1 \%$.

To improve the overall calibration, actual WWTW discharge volumes and water qualities will be required. The calibration result is deemed satisfactory considering data restrictions and the assumption that the phosphates behave conservatively.

Modelled phosphate loads for the segments between gauges in the network, forms part of the calibration set and these calibrated loads are representative of the diffuse phosphate sources. These diffuse sources relate to wash off and shallow groundwater seepage into the streams and rivers. Phosphate contributions from informal settlements (Fig. 4) are then by implication also contained within this term. 

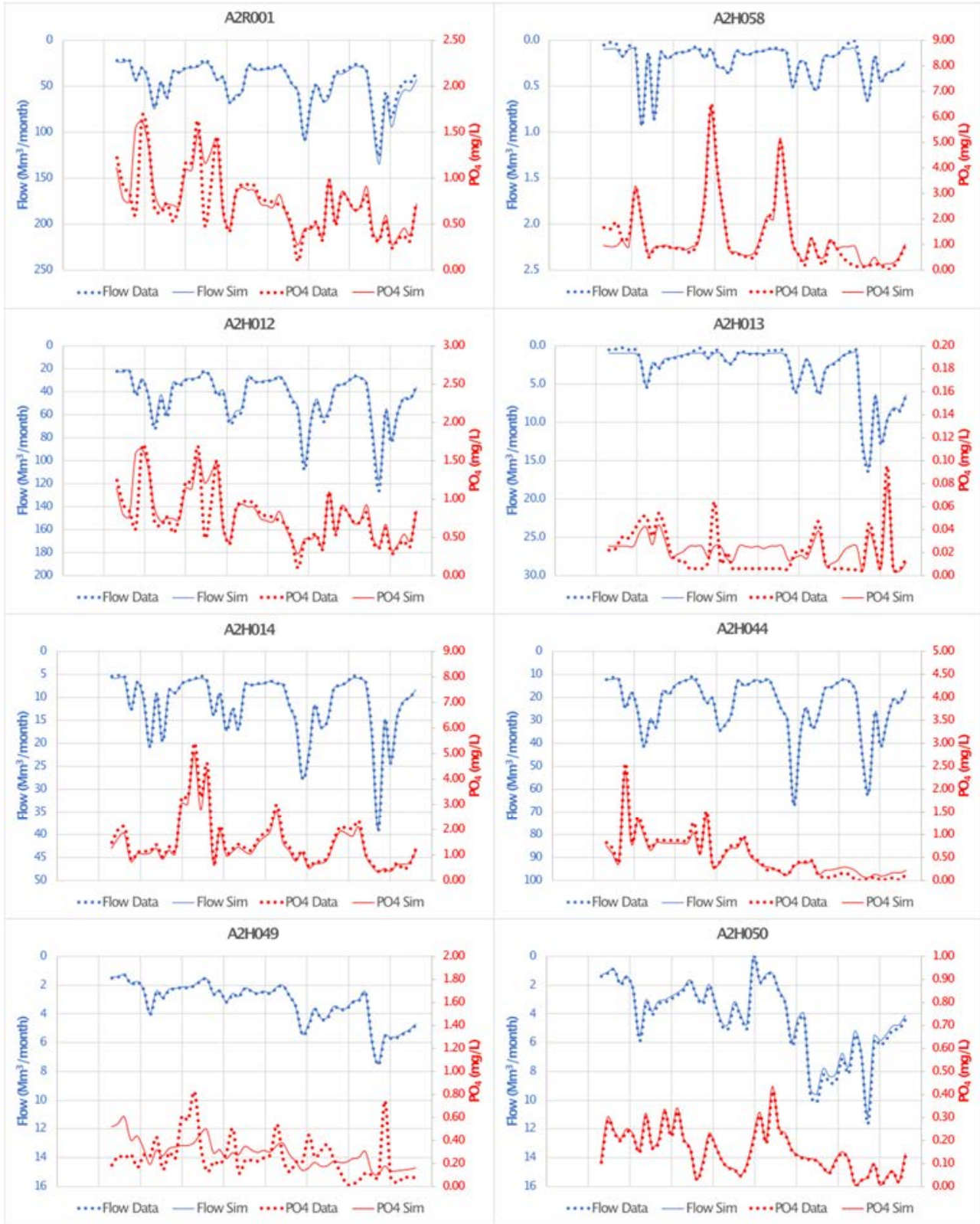

Figure 10: Network calibration results.

\subsection{Modelled scenarios}

It has been shown earlier that the WWTWs are considered as the main culprit in the eutrophication state of the Hartbeespoort Dam. When considering the extreme case where all WWTWs are simulated with a zero-phosphate concentration, the total phosphate load at the 
inflow of the dam is reduced by nearly $40 \%$. The average resultant phosphate concentration is then $0.39 \mathrm{mg} / \mathrm{L}$ which still does not reach the $0.15 \mathrm{mg} / \mathrm{L}$ target required to inhibit algae growth.

Mine decant took place at Tweelopiespruit (upstream of gauge A2H049) during the calibration period. The phosphate concentrations of the decant water are very low $(\sim 0.01$ $\mathrm{mg} / \mathrm{L}$ ), and do not make a significant contribution to the final phosphate load. Currently the mine decant has ceased due to pumping of the mine water. The decant volume was roughly $3 \%$ of the total inflow to the dam and the loss of this flow volume has an insignificant effect on the total phosphate load.

A detailed study of each informal settlement would be required to quantify the phosphate load emanating from each of them. However, a first estimate can be obtained by using some of the catchments within the study area as reference. For this scenario, the phosphate concentrations for all the WWTWs was set to zero. To obtain an estimate for background phosphate concentrations, gauge A2H050 was used as the land cover comprise of mainly of small holdings and urban areas. The average phosphate concentration is $0.151 \mathrm{mg} / \mathrm{L}$ which coincidentally compares with the $0.15 \mathrm{mg} / \mathrm{L}$ target concentration required at the dam inflow. The Magalies River catchment was chosen to get an indication of the contribution of agricultural activities to the phosphate load, since the land cover of this catchment is predominately natural with agricultural activities (see Fig. 1). The average phosphate concentration was calculated as $0.297 \mathrm{mg} / \mathrm{L}$ and it is assumed this concentration includes the estimated background phosphate concentration of $0.151 \mathrm{mg} / \mathrm{L}$. Since $93 \%$ of the flow to the dam originate upstream from gauge $\mathrm{A} 2 \mathrm{H} 012$, the average phosphate concentrations at this point was calculated as $0.432 \mathrm{mg} / \mathrm{L}$, bearing in mind all WWTWs were set to have zero phosphate concentrations. This results in an average net contribution of $0.135 \mathrm{mg} / \mathrm{L}$ phosphates that are assumed to be contributed from the informal settlements. By also removing this contribution, in addition to the phosphate load from the WWTWs, the phosphate load entering the dam is reduced by $60.6 \%$ which translates to a phosphate concentration of $0.284 \mathrm{mg} / \mathrm{L}$ at the dam inflow.

\section{CONCLUSIONS AND RECOMMENDATIONS}

A water quality model, used to simulate the phosphate concentrations within the Hartbeespoort catchment, was successfully setup and a good calibration was achieved, considering the assumption that phosphates behave conservatively in water courses.

Existing monitoring data was used for calibration purposes. Data from October 2007 to July 2011 were used, mainly because the flow gauges have good continuous data over this period and data verification and corrections to the dataset was performed during a previous project. Calibration was performed by making use of a GA, which minimises the RMSE between simulated and observed values at every monitoring point and uses the Elitist selection algorithm. Unknown phosphate loads within the system were treated as calibration parameters and are therefore only presented as constant values within the network.

An extreme scenario was considered where the phosphate concentrations of all the WWTWs were reduced to zero to determine the impact of the phosphate load entering the dam. This resulted in a $40 \%$ reduction in the phosphate concentration to $0.39 \mathrm{mg} / \mathrm{L}$ which still does not meet the target of $0.15 \mathrm{mg} / \mathrm{L}$. The impact of the mine water decant was also investigated, but was deemed negligible.

Informal settlements along streams also contribute a to the total nutrient load entering the dam. In a first estimate of possible phosphate contributions from informal settlements, it was estimated that they contribute roughly $20 \%$ of the phosphate load to the dam. It is however stressed that a detail assessment of these settlements is required to give more accurate 
predictions regarding possible impacts. These settlements are a result of social circumstances and to relocate the inhabitants is not always practical solution. A social paradigm shift is required in the form of social upliftment. It is recommended that practices that have emerged as powerful upliftment tools [19] should be implemented. Examples of these upliftment tools include education of the local women, as they are responsible for feeding the household and ensuring there is water; and partnerships between government, international organisations and academics to assist in improving housing, facilities and education.

Finally, it is concluded that to reach the $0.15 \mathrm{mg} / \mathrm{L}$ target for phosphate concentrations entering the dam, the phosphate contributions from both the WWTWs and diffuse sources in the catchment needs to be addressed.

\section{ACKNOWLEDGEMENT}

A special word of thanks to Dr Theuns De Klerk for making the map of the study area available for this paper.

\section{REFERENCES}

[1] Van der Merwe-Botha, M., Water quality: A vital dimension of water security. Development Planning Division, Working Paper Series, No.14, DBSA: Midrand, 2009.

[2] Harties Metsi A Me, Hartbeespoort Dam integrated biological remediation programme: Department of Water and Sanitation. www.harties.org.za/algae.aspx. Accessed on: 21 Jun. 2018.

[3] Czernowalow, M., Municipalities: The blame game - Harties sewage spill. www.waterafrica.co.za/index.php/features/effluent-industrial-waste/32-municipalthe-blame-game-harties-sewage-spill. Accessed on: 28 Nov. 2018.

[4] Mema, V., Impact of poorly maintained wastewater and sewage treatment plants: Lessons from South Africa. https://pdfs.semanticscholar.org/afa6/d6ff3a25061a5c9b8 f2194680f1b5c682fbc.pdf. Accessed on: 28 Aug. 2019.

[5] DH Environmental Consulting, South Africa's eutrophication nemesis: Hartbeespoort Dam.

http://blog.dhec.co.za/2011/05/south-africas-eutrophication-nemesis-hartbeespoortdam. Accessed on: 21 Sep. 2019.

[6] Institute for Water Quality Studies, Department of Water Affairs and Forestry, Towards a classification system for water resources in South Africa. www.dwa.gov.za/iwqs/waterlaw/present/towards_classification.htm. Accessed on: 21 Sep. 2019.

[7] Farmer's Weekly, Water quality and quantity reach crisis levels. www.farmersweekly.co.za/agri-news/south-africa/water-quality-and-quantity-reachcrisis-levels/. Accessed on: 30 Aug. 2019.

[8] Jacarandafm, Harties Dam invaded by algae due to sewage spills. www.jacarandafm.com/shows/the-complimentary-breakfast-with-rian-van-heerden/ harties-dam-invaded-algae-due-sewage-spills/. Accessed on: 30 Aug. 2019.

[9] International Bank for Reconstruction and Development/The World Bank, Overcoming poverty and inequality in South Africa: An assessment of drivers, constraints and opportunities.

[10] Alexander, P., Rebellion of the poor: South Africa's service delivery protests - A preliminary analysis. Review of African Political Economy, 37(123), 2010. 
[11] Venter, P.S., Hartbeespoort Dam integrated biological remediation programme addressing hypertrophic conditions by enhancing aquatic ecosystem bio-diversity. Southern African Society of Aquatic Scientists, 49th Congress, 2012.

[12] Harding, W.R., The determination of annual phosphorus loading limits for South African dams. Water Research Commission Report, No 1687/1/08, 2008.

[13] Department of Water and Sanitation, Hydrological services: Surface water (data, dams, floods and flows). www.dwaf.gov.za/Hydrology. Accessed on: 28 Nov. 2018.

[14] Department of Water and Sanitation, Resource quality information services data and reports. www.dwa.gov.za/iwqs/report.aspx. Accessed on: 28 Nov. 2018.

[15] Huizenga J., Silberbauer, M., Dennis, R. \& Dennis, I., An inorganic water chemistry dataset (1972-2011) of rivers, dams and lakes in South Africa. Water SA, 39(2), 2013.

[16] Vollenweider R.A., Input-output models with special reference to the phosphorous loading concept in limnology. Schweiz. Z. Hydrol., 37, pp. 53-83, 1975.

[17] Loucks, D.P. \& Van Beek, E., Water Resources Systems Planning And Management. UNESCO, 2005.

[18] Karr, L.C., Stanley, D.A. \& Scheiner, B.J., Genetic algorithm applied to least squares curve fitting. Report of Investigations 9339, US Bureau of Mines, US Department of Interior, 1991.

[19] Hendler, Y. \& Fieuw, W., Exploring partnerships with local government: A people's led approach to informal settlement upgrading. Community Organisation Resource Centre, Cape Town, 2018.

[20] De Klerk, T.C., Hartbeespoort catchment map set. North-West University Internal Dataset, 2015.

[21] Kormorant, Hartbeespoort water birds in crisis. www.kormorant.co.za/28853/ hartbeespoort-water-birds-in-crisis. Accessed on: 7 Jul. 2018.

[22] Venter, P.S., New hope for troubled waters: The Hartbeespoort Dam test case. The Water Wheel, 2004.

[23] News24, Rats and floods: Just part of life along the Jukskei River. www.news24.com/SouthAfrica/News/rats-and-floods-just-part-of-life-along-thejukskei-river-20190101. Accessed on: 28 Aug. 2019.

[24] Mail and Guardian, Buckets, pits and poverty: How the other half defecates. https://mg.co.za/article/2014-09-25-buckets-pits-and-poverty-how-the-other-halfdefecates. Accessed on: 28 Aug. 2019.

[25] Design Methods, Multi-objective optimization of a laminar transonic airfoil for swept wing. www.designmethods.it/CaseStudies-Aerospace/NLFairfoildesign.html. Accessed on: Jan. 2019. 